\title{
Phylogenetic Analysis of Borrelia burgdorferi Sensu Stricto by Arbitrarily Primed PCR and Pulsed-Field Gel Electrophoresis
}

\author{
MARC FORETZ, DANIÈLE POSTIC,* AND GUY BARANTON \\ Unité de Bactériologie Moléculaire et Médicale, Institut Pasteur, \\ 75724 Paris Cedex 15, France
}

\begin{abstract}
Borrelia burgdorferi sensu lato is present all over the world. However, most species belonging to this complex have a limited distribution; the only exception is $B$. burgdorferi sensu stricto, which is encountered both in Europe and in the United States. The aim of this study was to clarify the way that $B$. burgdorferi sensu stricto migrated. To do this, we compared the genetic polymorphism of 33 B. burgdorferi sensu stricto strains isolated in Europe and 28 strains isolated in the United States by using both pulsed-field gel electrophoresis and arbitrarily primed PCR. Phylogenetic analysis of each of the two sets of data was performed by a genetic distance method and a parsimony method. The results were consistent and revealed that the American strains were more heterogeneous than the European strains. The hypothesis that B. burgdorferi sensu stricto was introduced to Europe from America rather than vice versa has to be considered.
\end{abstract}

Borrelia burgdorferi sensu lato is a spirochete that is responsible for Lyme borreliosis, a disease with a wide spectrum of symptoms, ranging from minor cutaneous erythema to severe arthritis or neurological manifestations. This worldwide disease is transmitted to humans by Ixodidae ticks. The heterogeneous clinical presentation of the disease has been linked to the genetic diversity of the $B$. burgdorferi sensu lato complex, which has been divided into at least eight species or genomic groups (22). Borrelia garinii and Borrelia afzelii are encountered in Europe and Asia, whereas B. burgdorferi sensu stricto is present in the United States and in Europe but is absent from Asia $(19,33)$. Until recently, B. burgdorferi sensu stricto was considered the only species that occurs in North America. Several genetic studies have shown that $B$. burgdorferi sensu stricto strains isolated from both the Old World and the New World exhibit a high degree of similarity. There is a question concerning the direction of migration of $B$. burgdorferi sensu stricto strains. Two hypotheses can be proposed. One hypothesis is that a long time ago, an ancestor strain of B. burgdorferi sensu stricto migrated to America from Europe, where it had evolved for a long time. The ability of migratory birds to spread Borrelia strains (21) makes such a migration likely. This hypothesis is supported by the existence of several highly divergent species in Eurasia compared with an apparent unicity in America, suggesting that the whole Lyme borreliosis complex originated in Eurasia. However, the discovery of at least two other genospecies in the United States, Borrelia andersonii (20) and group DN127, led us to examine whether B. burgdorferi sensu stricto could have originated in America before it migrated to Europe.

In order to further investigate the evolution of $B$. burgdorferi sensu stricto and the migration route from west to east or vice versa, two methods, pulsed-field gel electrophoresis (PFGE) and arbitrarily primed PCR (AP-PCR) were used to compare the genetic polymorphism of European and American strains.

* Corresponding author. Mailing address: Unité de Bactériologie Moléculaire et Médicale, Institut Pasteur, 28 rue du Docteur Roux, 75724 Paris Cedex 15, France. Phone: 331456883 37. Fax: 3314061 30 01. E-mail: dpostic@pasteur.fr.

\section{MATERIALS AND METHODS}

Bacterial strains. The $61 \mathrm{~B}$. burgdorferi sensu stricto isolates used in this study are listed in Table 1; 33 of these strains were isolated in Europe, and 28 strains were isolated in North America. The organisms were chosen from our collection so that the greatest possible geographic diversity for each continent was represented. Strain DN127, a member of genomic group DN127, was used as an outgroup strain for phylogenetic studies. The isolates were grown in BSK-H medium (Sigma) supplemented with $6 \%$ rabbit serum at $30^{\circ} \mathrm{C}(4)$.

PFGE. Previously described procedures were used to prepare high-molecularweight genomic DNAs and for PFGE $(6,7,9)$. Separation of DNA fragments was achieved with a pulse time ramped from 3 to $50 \mathrm{~s}$ for $30 \mathrm{~h}$ with a contour-clamped homogeneous electric field model DRII apparatus (Bio-Rad Laboratories, Richmond, Calif.). To separate restriction fragments shorter than $50 \mathrm{kbp}$, we used zero-integrated-field electrophoresis (ZIFE) with the AutoBase system (Techgen Company, Les Ulis, France). The ROM card allowing separation of fragments ranging in size from 8 to $50 \mathrm{kbp}$ was used. Rare cutting endonucleases $M l u \mathrm{I}$, Bss HII, and SacII were used to differentiate isolates. Lambda concatemers (monomer size, $48.5 \mathrm{kbp}$ ) purchased from New England Biolabs, Beverly, Mass., and contour-clamped homogeneous electric field DNA size standards ( 8 to 48 $\mathrm{kbp}$; Bio-Rad) were used as size markers with the Bio-Rad apparatus and the ZIFE apparatus, respectively. Strains which exhibited the same PFGE pattern with $M l u \mathrm{I}$, the same PFGE pattern with Bss HII, and the same PFGE pattern with SacII were placed in the same PFGE polymorphism group; different groups were designated groups $\mathrm{A}$ to $\mathrm{S}$.

DNA blot analysis. For blot experiments as described by Southern (25), DNA fragments separated by PFGE were subjected to depurination and transferred to Hybond- $\mathrm{N}$ nylon membranes (Amersham). To prepare a probe, the chromosomal band from isolate 212 was excised from a low-melting-temperature agarose pulsed-field gel, washed twice in TE $(10 \mathrm{mM}$ Tris- $\mathrm{HCl}, 1 \mathrm{mM}$ EDTA [pH $8.0]$ ), and digested with $M l u \mathrm{I}$ or Bss HII as described above. Labelling was performed by random priming with digoxigenin-11-dUTP as previously described (5). Hybridized fragments were revealed with an anti-digoxigenin antibody conjugated with alkaline phosphatase and CSPD, a chemoluminescent substrate, by using the procedure recommended by the manufacturer (Boehringer). The membranes were exposed for $15 \mathrm{~min}$.

DNA preparation. Isolates in BSK-H medium were incubated at $30^{\circ} \mathrm{C}$ for 7 to 12 days until the density was about $10^{8}$ cells per ml. Cells were harvested, washed in phosphate-buffered saline, resuspended in distilled water, and finally boiled at $110^{\circ} \mathrm{C}$ for $15 \mathrm{~min}$. Thermolysates were stored at $-20^{\circ} \mathrm{C}$ before they were used for AP-PCR experiments.

AP-PCR fingerprinting. Fingerprinting was performed as described previously (31), with minor modifications. The reaction mixtures $(25 \mu \mathrm{l})$ contained $5 \mu \mathrm{l}$ of bacterial thermolysate, $1 \times$ Taq polymerase buffer $(10 \mathrm{mM}$ Tris $[\mathrm{pH} 8.3], 50 \mathrm{mM}$ $\mathrm{KCl}, 4 \mathrm{mM} \mathrm{MgCl}$ ), each deoxynucleoside triphosphate at a concentration of 0.2 $\mathrm{mM}$, single oligonucleotide primers at concentrations of 1 to $5 \mu \mathrm{M}$, and $0.625 \mathrm{U}$ of Taq polymerase (Amersham), and $4 \mu \mathrm{Ci}$ of $\left[\alpha^{-{ }^{33}} \mathrm{P}\right] \mathrm{dATP}$ (ICN Pharmaceuticals, Inc., Costa Mesa, Calif.) was added to each mixture. The following primers were purchased from Genset, Paris, France: RSP (5'-GGAAACAGCTATGAC CATGA-3') (6), SP (5'-TTGTAAAACGACGGCCAG-3') (6), T5B (5'-AATG CTCTACCAACTGAACT-3') (7), T3 (5'-GCAATTAACCCTCACTAAAG-3') (7), and OspC1 (5'-AGTGCGATATT(AG)ATGACTTT-3'). The reaction mixtures were subjected twice to the following low-stringency temperature profile 
TABLE 1. Strains used in this study

\begin{tabular}{|c|c|c|c|c|c|}
\hline Isolate & $\begin{array}{l}\text { PFGE polymorphism } \\
\text { group }\end{array}$ & $\begin{array}{l}\text { Lane(s) on } \\
\text { AP-PCR gel }{ }^{a}\end{array}$ & $\begin{array}{c}\text { Geographical } \\
\text { origin }\end{array}$ & Source & $\begin{array}{l}\text { Person who } \\
\text { provided }\end{array}$ \\
\hline Charlie tick & A & 63 & Wisconsin & Ixodes scapularis & C. Kodner \\
\hline Veery & $\mathrm{B}$ & 42 & Connecticut & Veery bird & R. T. Marconi \\
\hline 297 & $\mathrm{C}$ & 48 & Connecticut & Human cerebrospinal fluid & \\
\hline NY13-87 & $\mathrm{C}$ & 26 & New York & Human skin & R. T. Marconi \\
\hline VS 2 & $\mathrm{C}$ & 43 & Shelter Island, N.Y. & Ixodes scapularis & O. Péter \\
\hline Sh2-82 & $\mathrm{C}$ & 34 & Texas & Ixodes scapularis & S. Bergström \\
\hline CA2-87 & $\mathrm{D}$ & 21 & California & Ixodes pacificus & R. T. Marconi \\
\hline HUM 115 & D & 27 & California & Ixodes pacificus & M. Janda \\
\hline HUM 7814 & $\mathrm{E}$ & 8 & California & Ixodes pacificus & M. Janda \\
\hline HB19 & $\mathrm{E}$ & 37 & Connecticut & Human blood & A. Barbour \\
\hline CA6 & $\mathrm{F}$ & 23 & California & Ixodes pacificus & R. Lane \\
\hline MEN115 & $\mathrm{F}$ & 59 & California & Ixodes pacificus & M. Janda \\
\hline HUM 3336 & $\mathrm{~F}$ & 60 & California & Ixodes pacificus & M. Janda \\
\hline CA5 & $\mathrm{F}$ & 61 & California & Ixodes pacificus & R. Lane \\
\hline SON 188 & G & 15 & California & Ixodes pacificus & M. Janda \\
\hline LAKE 339 & G & 52 & California & Ixodes pacificus & M. Janda \\
\hline NY1-86 & $\mathrm{H}$ & 51 & New York & Human skin & R. T. Marconi \\
\hline SON 2110 & I & 16 & California & Ixodes pacificus & M. Janda \\
\hline 21343 & $\mathrm{~J}$ & 9 & Wisconsin & Peromyscus leucopus & J. F. Anderson \\
\hline 21305 & $\mathrm{~K}$ & 50 & Connecticut & Peromyscus leucopus & J. F. Anderson \\
\hline SON 335 & $\mathrm{~L}$ & 10 & California & Ixodes pacificus & M. Janda \\
\hline SON 328 & $\mathrm{~L}$ & 19 & California & Ixodes pacificus & M. Janda \\
\hline SV1 & M & 49 & France & Ixodes ricinus & C. Perez \\
\hline 35B 808 & $\mathrm{M}$ & 33 & Germany & Ixodes ricinus & A. Schönberg \\
\hline HII & $\mathrm{N}$ & 47 & Italy & Human blood & V. Sambri \\
\hline DK7 & $\mathrm{O}$ & 5 & Denmark & Human skin & M. Theisen \\
\hline SV4 & $\mathrm{O}$ & 25 & France & Ixodes ricinus & C. Perez \\
\hline 212 & $\mathrm{O}$ & 39 & France & Lxodes ricinus & F. Milward \\
\hline 20006 & $\mathrm{O}$ & 44 & France & Lxodes ricinus & J. F. Anderson \\
\hline GeHo & $\mathrm{O}$ & 20 & Germany & Human skin & Vögel \\
\hline 61BV3 & $\mathrm{O}$ & 28 & Germany & Human skin & A. Schönberg \\
\hline ZS7 & $\mathrm{O}$ & 31 & Germany & Ixodes ricinus & L. Gern \\
\hline Z118 & $\mathrm{O}$ & 45 & Germany & Ixodes ricinus & A. Vogt \\
\hline ESP-1 & $\mathrm{O}$ & 7 & Spain & Lxodes ricinus & R. C. Johnson \\
\hline IRS & $\mathrm{O}$ & 24 & Switzerland & Lxodes ricinus & \\
\hline NE493 & $\mathrm{O}$ & 29 & Switzerland & Ixodes ricinus & L. Gern \\
\hline NE456 & $\mathrm{O}$ & 30 & Switzerland & Ixodes ricinus & L. Gern \\
\hline MIL & $\mathrm{P}$ & 18 & Slovakia & Ixodes ricinus & A. Livesley \\
\hline Y1 & $\mathrm{Q}$ & 14 & Finland & Lxodes ricinus & J. Tuomi \\
\hline SV3 & $\mathrm{Q}$ & 62 & France & Ixodes ricinus & C. Perez \\
\hline Z136 & $\mathrm{Q}$ & 11 & Germany & Ixodes ricinus & A. Vogt \\
\hline NE196 & Q & 13 & Switzerland & Ixodes ricinus & L. Gern \\
\hline NE56 & $\mathrm{R}$ & 12 & Switzerland & Ixodes ricinus & L. Gern \\
\hline Holzer & $\mathrm{S}$ & 1,2 & Austria & Human blood & G. Stanek \\
\hline Lenz & $\mathrm{S}$ & 3 & Austria & Human heart muscle & G. Stanek \\
\hline $\mathrm{H} 3$ & $\mathrm{~S}$ & 22 & Austria & Human skin & G. Stanek \\
\hline $\mathrm{T}$ & $\mathrm{S}$ & 35 & Austria & Human skin & G. Stanek \\
\hline $\mathrm{H} 1$ & $\mathrm{~S}$ & 41 & Austria & Human skin & G. Stanek \\
\hline L5 & $\mathrm{S}$ & 46 & Austria & Human skin & G. Stanek \\
\hline P1F & $\mathrm{S}$ & 4 & Austria & Human synovial fluid & G. Stanek \\
\hline $\mathrm{Hb} 1$ & $\mathrm{~S}$ & 32 & Austria & Mouse & G. Stanek \\
\hline IP2 & $\mathrm{S}$ & 55 & France & Human cerebrospinal fluid & G. Baranton \\
\hline IP3 & $\mathrm{S}$ & 36 & France & Human cerebrospinal fluid & G. Baranton \\
\hline IP1 & $\mathrm{S}$ & 54 & France & Human cerebrospinal fluid & G. Baranton \\
\hline PKa & $\mathrm{S}$ & 40 & Germany & Ixodes ricinus & V. Preac Mursic \\
\hline $\mathrm{B} 31^{\mathrm{T}}$ & $\mathrm{S}$ & 6 & New York & Ixodes scapularis & \\
\hline 19535 & $\mathrm{~S}$ & 58 & New York & Peromyscus leucopus & J. F. Anderson \\
\hline 26816 & $\mathrm{~S}$ & 56 & Rhode Island & Microtus pennsylvanicus & J. F. Anderson \\
\hline 27985 & $\mathrm{~S}$ & 57 & Shelter Island, N.Y. & Ixodes scapularis & J. F. Anderson \\
\hline Cat Flea & $\mathrm{S}$ & 53 & Texas & Ctenocephalides felis & D. Ralph \\
\hline 1352 & $\mathrm{~S}$ & 17 & Texas & Ixodes scapularis & R. T. Marconi \\
\hline DN127 & & 38 & California & Ixodes pacificus & M. Janda \\
\hline
\end{tabular}

${ }^{a}$ See Fig. 3. 
A

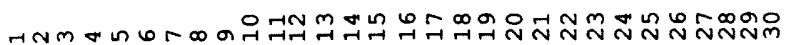

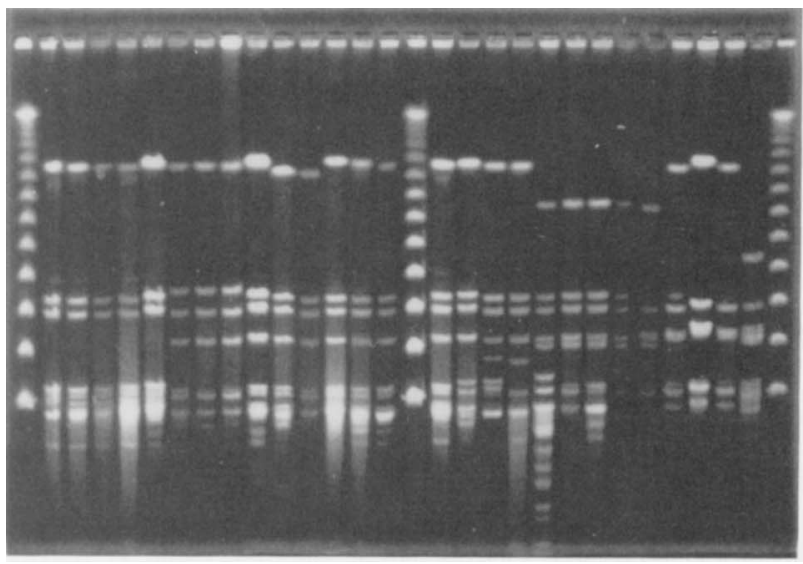

B
Nm

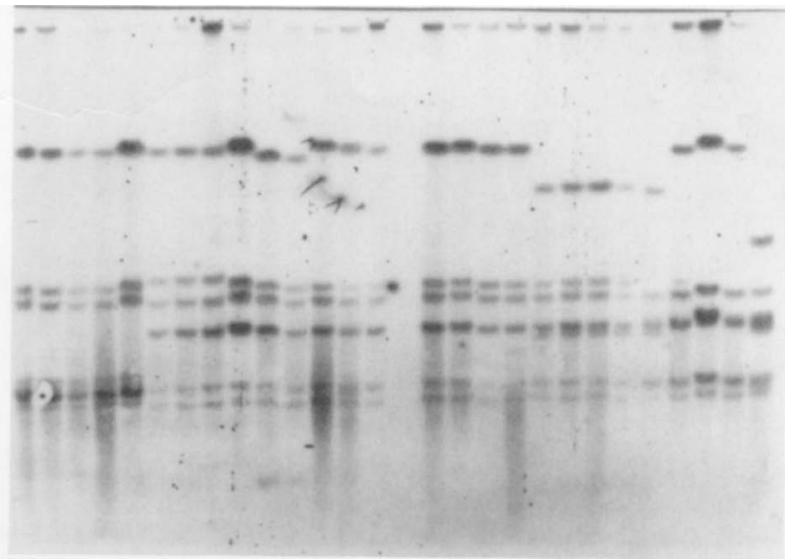

FIG. 1. (A) Mlu1 restriction profiles of B. burgdorferi sensu stricto strains obtained with the Bio-Rad apparatus with the pulse time ramped from 3 to $50 \mathrm{~s}$ for $30 \mathrm{~h}$. (B) Blot of the PFGE gel hybridized with the chromosomal fragment from B. burgdorferi 212 DNA. The lanes contained lambda concatemers (lanes 1, 16, and 30) and DNAs from isolates Cat Flea (lane 2), L5 (lane 3), T (lane 4), Hb1 (lane 5), B31 (lane 6), CA5 (lane 7), MEN115 (lane 8), HUM 3336 (lane 9), 212 (lane 10), HB19 (lane 11). HUM 7814 (lane 12), NY13-87 (lane 13), Sh2-82 (lane 14), NE493 (lane 15), 61BV3 (lane 17), MIL (lane 18), 20006 (lane 19 ), Z118 (lane 20 ), SON 328 (lane 21), SON 335 (lane 22), SV3 (lane 23), Z136 (lane 24), 21305 (lane 25), LAKE 339 (lane 26), NY1-86 (lane 27), SON 188 (lane 28), and Veery (lane 29).

cycle: denaturation at $94^{\circ} \mathrm{C}$ for $5 \mathrm{~min}$, low-stringency annealing at $40^{\circ} \mathrm{C}$ for $5 \mathrm{~min}$, and extension at $72^{\circ} \mathrm{C}$ for $5 \mathrm{~min}$. These cycles were followed by $40 \mathrm{high}$-stringency temperature profile cycles $\left(94^{\circ} \mathrm{C}\right.$ for $1 \mathrm{~min}, 60^{\circ} \mathrm{C}$ for $1 \mathrm{~min}$, and $72^{\circ} \mathrm{C}$ for $2 \mathrm{~min}$ ) Thermocycling was performed with a model OmniGene apparatus (Hybaid).
Each reaction mixture was combined 1:1 ( $\mathrm{vol} / \mathrm{vol})$ with $98 \%$ formamide dye and heated to $95^{\circ} \mathrm{C}$ for $15 \mathrm{~min}$ before it was loaded onto a $6 \%$ acrylamide-50\% urea sequencing gel. Electrophoresis was carried out at $1,800 \mathrm{~V}$ and $80 \mathrm{~W}$ for $3.5 \mathrm{~h}$. The gels were dried and exposed for $24 \mathrm{~h}$.

-

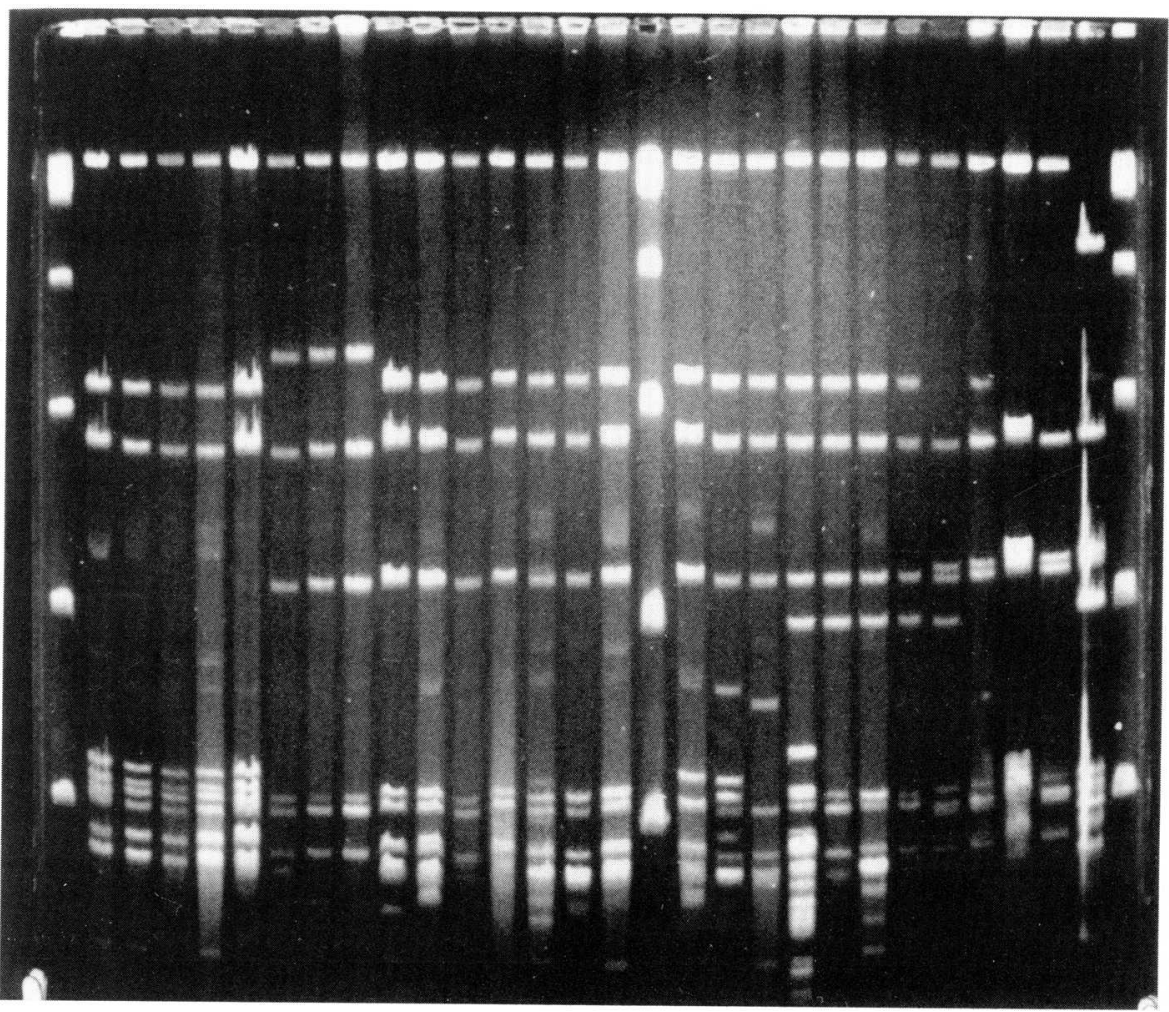

FIG. 2. MluI restriction profiles of the strains in Fig. 1 obtained by the ZIFE method with the 100- to 150-kbp ROM card. The lanes contained lambda concatemers (lanes 1, 17, and 30) and DNAs from isolates Cat Flea (lane 2), L5 (lane 3), T (lane 4), Hb1 (lane 5), B31 ${ }^{\mathrm{T}}$ (lane 6), CA5 (lane 7), MEN115 (lane 8), HUM 3336 (lane 9), 212 (lane 10), HB19 (lane 11), HUM 7814 (lane 12), NY13-87 (lane 13), Sh2-82 (lane 14), NE493 (lane 15), 61BV3 (lane 16), MIL (lane 18), 20006 (lane 19), Z118 (lane 20), SON 328 (lane 21), SON 335 (lane 22), SV3 (lane 23), Z136 (lane 24), 21305 (lane 25), LAKE 339 (lane 26), NY1-86 (lane 27), SON 188 (lane 28), and Veery (lane 29). 
Phylogenetic analysis. To analyze the fingerprint data, we used the following three phylogenetic inference packages: PAUP (phylogenetic analysis using parsimony) (26), PHYLIP (phylogeny inference package) (10), and MEGA (molecular evolutionary genetics analysis) (17). The fingerprint data were collected and analyzed in blind experiments. Strain DN127, a member of genomic group DN127, was found to be closely related to $B$, burgdorferi sensu stricto (level of DNA relatedness, 57 to $67 \%$; difference between the melting temperature of the homologous hybrid and the melting temperature of the heterologous hybrid, 5 to $\left.7^{\circ} \mathrm{C}\right)(22)$. Thus, strain DN127 was used as an outgroup in the phylogenetic analysis.

\section{RESULTS AND DISCUSSION}

Genomic fingerprinting by PFGE. Because the $B$. burgdorfer genome has a $\mathrm{G}+\mathrm{C}$ content of 27 to $30 \mathrm{~mol} \%(3,14)$, restriction endonucleases with $\mathrm{G} \cdot \mathrm{C}$-rich recognition sequences were used to cut the DNA into sufficient numbers of fragments to allow interpretable comparisons. Restriction endonucleases $M l u I, B s s H I I$, and SacII were chosen to do this since they had generated great polymorphism among $B$. burgdorferi sensu stricto strains previously $(7,8)$. The $M l u I$ patterns obtained under two different conditions of electrophoresis are shown in Fig. 1 and 2. When the model DRII apparatus (Bio-Rad) was used, the large fragments (fragments larger than $300 \mathrm{kbp}$ ) were well resolved (Fig. 1A). A 100- to 150-kbp ROM card was used to separate the 100- to 200-kbp fragments (Fig. 2). Fragments smaller than $50 \mathrm{kbp}$ were visualized by using the $8-$ to $50-\mathrm{kbp}$ ROM card (data not shown). However, in the low-molecularweight range, the presence of plasmids made interpretation of the PFGE patterns difficult. Thus, it was impossible to distinguish whether DNA fragments smaller than $80 \mathrm{kbp}$ were intact or plasmid fragments or cut chromosomes. To answer this question, each PFGE gel was transferred to a nylon membrane and hybridized with a chromosomal probe prepared from strain 212 (Fig. 1B). When this was done, the chromosomal fragments were easily recognized. However, this method did not allow us to visualize chromosomal fragments smaller than $10 \mathrm{kbp}$. Using MluI, BssHII, and SacII, we obtained 9, 12, and 6 restriction patterns, respectively. The sizes of the restriction fragments obtained after digestion by the three enzymes are shown in Table 2. An analysis of all of the results allowed us to define 19 polymorphism groups, which were designated groups A to $S$ (Table 1), for the $61 \mathrm{~B}$. burgdorferi sensu stricto strains studied. These results confirmed the high degree of heterogeneity of genetic patterns for $B$. burgdorferi sensu stricto reported previously (7). A total of 12 of the 19 groups contained only American strains (groups A to L), 6 groups contained only European strains (groups M to R), and 1 group contained both American and European strains (group S). Moreover, 24 of the 33 European strains studied belonged to only two groups. Clearly, these results confirmed the assumption that American strains are more heterogeneous than European strains.

The size of the chromosome deduced from the analysis of MluI and SacII fragments was 935 to $950 \mathrm{kbp}$, which was completely consistent with previously published results $(6,11)$. After restriction by the three enzymes, a genetic map was constructed (data not shown), and it was noteworthy that a supplementary 10 - to $15-\mathrm{kbp}$ fragment was found on the leftend fragment on the chromosome maps of strains belonging to American polymorphism group $\mathrm{F}$. Moreover, variation in the length of the right-end fragment of 18,24 , or $33 \mathrm{kbp}$ according to the polymorphism group was also observed when the BssHII fragments were analyzed. However, all of the European polymorphism groups were homogeneous in this respect (all had a $24-\mathrm{kbp}$ fragment). Considering the linear structure of the chromosome in the genus Borrelia, this variation in length at the extremities could be linked to the mechanism of replication of the spirochetes.

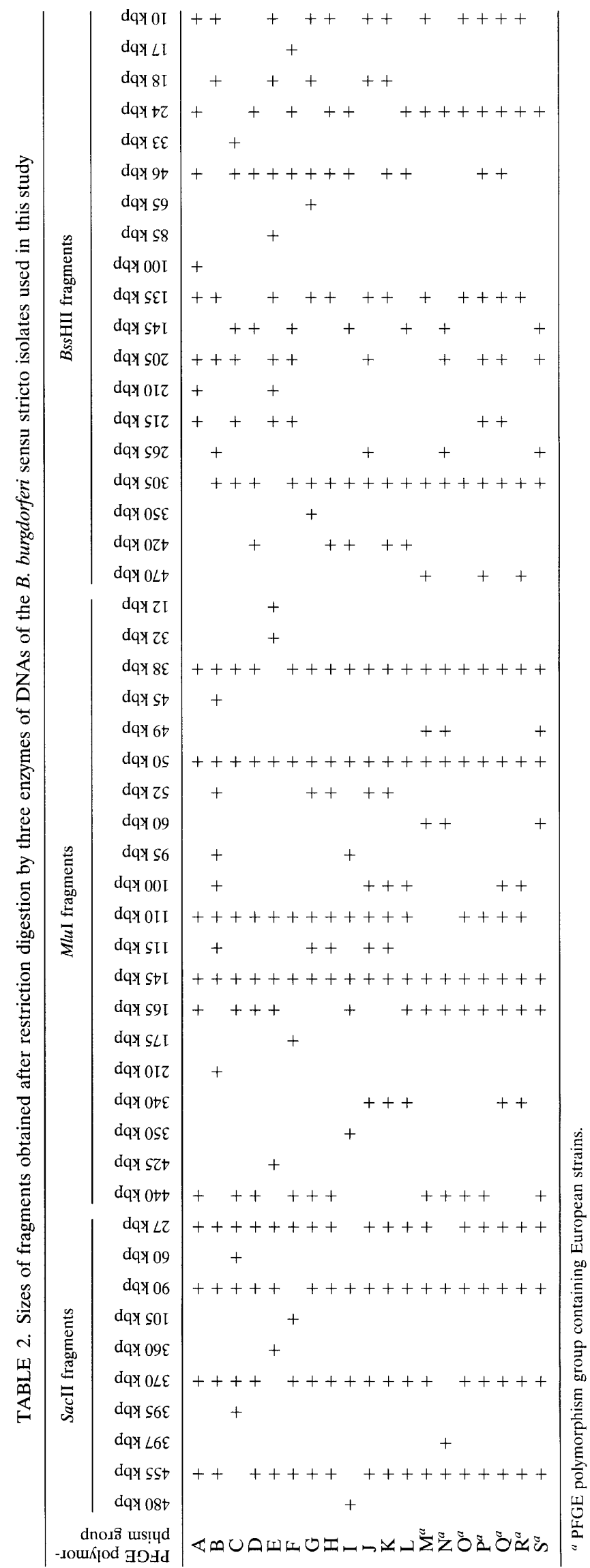




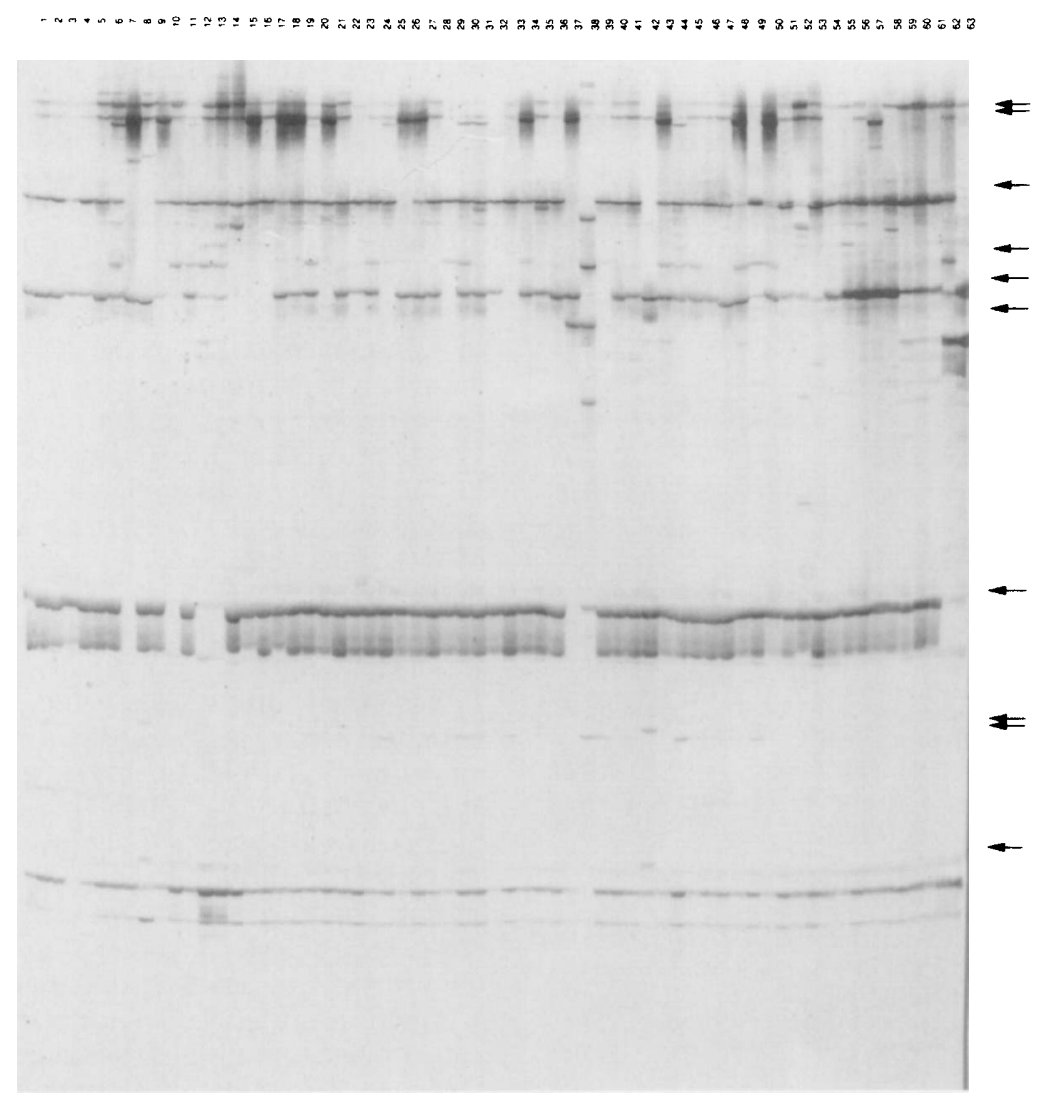

FIG. 3. AP-PCR fingerprints of the B. burgdorferi sensu stricto strains listed in Table 1 obtained with primer T5B. The arrows indicate polymorphic characters used to construct the data matrix.

Genomic fingerprinting by AP-PCR. AP-PCR was developed by Welsh et al. (30) to generate polymorphic fingerprints in order to distinguish variability between strains within a species or between strains belonging to closely related species. Discrete fingerprints reflect sequence differences scattered on the genome and therefore can be used to measure genetic distances and to establish phylogenetic relationships at an interspecific level or, especially, at an intraspecific level. This approach was used previously to resolve three distinct phyletic groups in $B$. burgdorferi sensu lato, corresponding to the three main species, $B$. burgdorferi sensu stricto, $B$. garinii, and $B$. afzelii (31). In this study AP-PCR was used to determine the intraspecific variation in the patterns, which allowed us to compare the polymorphism of $B$. burgdorferi sensu stricto strains from Europe and from the United States.

The AP-PCR fingerprints of DNAs from B. burgdorferi sensu stricto strains consisted of reproducible sets of products. To increase the validity of the results, the same DNA preparations were studied concurrently with each primer, and all AP-PCR products obtained with one primer were run on the same gel. It has been shown previously that AP-PCR fingerprints markedly differ from one species to another, which led to the recognition of Borrelia species (31). In contrast, within a species, Borrelia strains shared a high number of fingerprints. However, about 10 polymorphic characters per primer were available to compare strains. The fingerprints obtained from 62 strains with primer T5B are shown in Fig. 3. Since no extensive genetic exchange has been demonstrated so far in B. burgdorferi sensu lato except for the plasmidic $\operatorname{ss} C$ gene $(15,19)$, phylogenetic conclusions may be deduced from the shared derived characters observed for $B$. burgdorferi sensu stricto.

Phylogenetic analysis. All PFGE and AP-PCR data were analyzed by both genetic distance and parsimony methods.

(i) PFGE data. The data obtained for all restriction fragments on the gels were transformed into a binary data matrix, in which each fragment was scored as 1 (present) or 0 (absent). Thus, the data from PFGE experiments in which enzymes $M l u \mathrm{I}, B s s \mathrm{HII}$, and SacII were used yielded a matrix of 62 strains $\times 49$ characters. In order to reduce the size of the data matrix and to facilitate the phylogenetic distance analysis, only one strain of each group was selected and a minimatrix was used to construct trees by genetic distance methods.

We used the Fitch + genetic distance algorithm (13) in the PHYLIP phylogenetic analysis package to construct trees from PFGE pairwise distance measurements. This algorithm estimates phylogeny from distance matrix data by minimizing the differences between observed and expected pairwise distances (12). The tree which was obtained is shown in Fig. 4. The sum of squares for this tree is 9.8, and the average standard deviation is $16 \%$. An extremely similar tree was obtained by using the neighbor-joining method (23) in the MEGA software (data not shown).

Figure 5 shows a phylogenetic tree estimated by parsimony analysis with the PAUP program. Parsimony methods search for minimal-length trees (i.e., trees that minimize the number of evolutionary changes needed to explain the available data under a prespecified set of constraints upon permissible character changes). This program was used in the heuristic search 


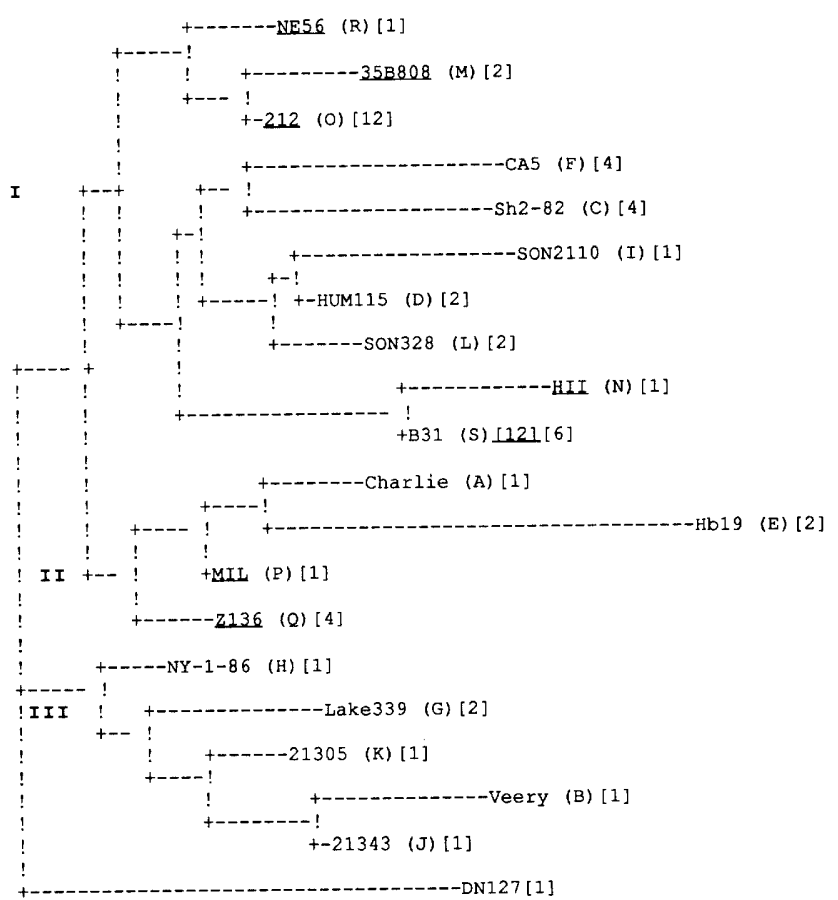

FIG. 4. Phylogenetic tree based on genetic distances and constructed by using the Fitch + genetic distance method in the PHYLIP package. The tree was generated from a reduced distance matrix for 20 taxa, each of which represented a PFGE polymorphism group. The European strains are underlined. The number of isolates in each group is indicated in brackets.

mode. The tree obtained was similar to the tree obtained by genetic distance analysis, except that polymorphism groups $\mathrm{C}$, $\mathrm{D}, \mathrm{F}, \mathrm{I}, \mathrm{L}, \mathrm{N}$, and S clustered in branch II instead of branch I as in the distance analysis. The consensus tree obtained by using the Mix+ parsimony algorithm in PHYLIP (data not shown) was similar to the tree obtained by using the parsimony analysis procedure in PAUP.

(ii) AP-PCR data. Each fragment on the gels was scored as 1 (present) or 0 (absent). Only unambiguous fragments were scored. Using five primers and 62 isolates, we scored 69 polymorphic characters which were shared by two or more taxa. All of the results yielded a data matrix that is available upon request. Our PHYLIP version could not be used due to the large number of recorded characters. Using the unweighted pair group with mathematical average method (24) in the MEGA program, we obtained the tree shown in Fig. 6. Similar results were obtained by using the neighbor-joining method (data not shown). Figure 7 shows a phylogenetic tree generated by using the heuristic search option in PAUP, which was extremely similar to the consensus tree obtained by distance analysis except that strains Son 2110 and NY1-86 branched differently in the two trees. As in the PFGE data analysis, all of the trees generated from the AP-PCR data analysis either by maximum parsimony or by genetic distance divided the 61 taxa into three major phylogenetic branches (branches I, II and III).

A total of 15 of the 33 European strains were grouped in PFGE polymorphism groups $\mathrm{M}, \mathrm{O}$, and $\mathrm{R}$, which were closely clustered in all of the trees. In a majority of the trees generated by the distance analysis and by the parsimony analysis, these three groups appeared on the same phylogenetic branch as groups $\mathrm{N}$ and $\mathrm{S}$. Group $\mathrm{S}$ was a mixed group containing both European and American strains; the PFGE patterns of these strains were identical, although the AP-PCR fingerprints were heterogeneous. The average pairwise genetic distances determined by the AP-PCR between strains belonging to groups $\mathrm{S}$ and $\mathrm{O}$ were $0.112(\sigma=0.053)$ and $0.136(\sigma=0.055)$, respectively, whereas the distance between groups $\mathrm{S}$ and $\mathrm{O}$ was 0.206 . The single strain in group $\mathrm{N}$ was closely related to group $\mathrm{S}$ strains. The European strains in group Q were located in a heterogeneous cluster together with American strains, although the distances reflected by the branch lengths were large.

American strains were scattered on all of the main phylogenetic branches and were separated by large genetic distances. Only one representative of group B and one representative of $\mathbf{J}$ revealed the deepest branch. Particularly noteworthy is the closeness between American type strain B31 and some European strains in mixed group S. Similarly, European groups $\mathrm{P}$ and $Q$ had American groups as their nearest neighbors.

To assess the range of genetic variation within B. burgdorferi sensu stricto, we used genetic markers which are widespread on the genome. A good correlation was observed between the two approaches used, as revealed by different phylogenetic computing methods, although AP-PCR identified more polymorphism groups than PFGE identified. We concluded two things from our study. First, greater polymorphism was observed among American strains than among European strains. Second, some American and European strains are closely related, which is consistent with the hypothesis that European

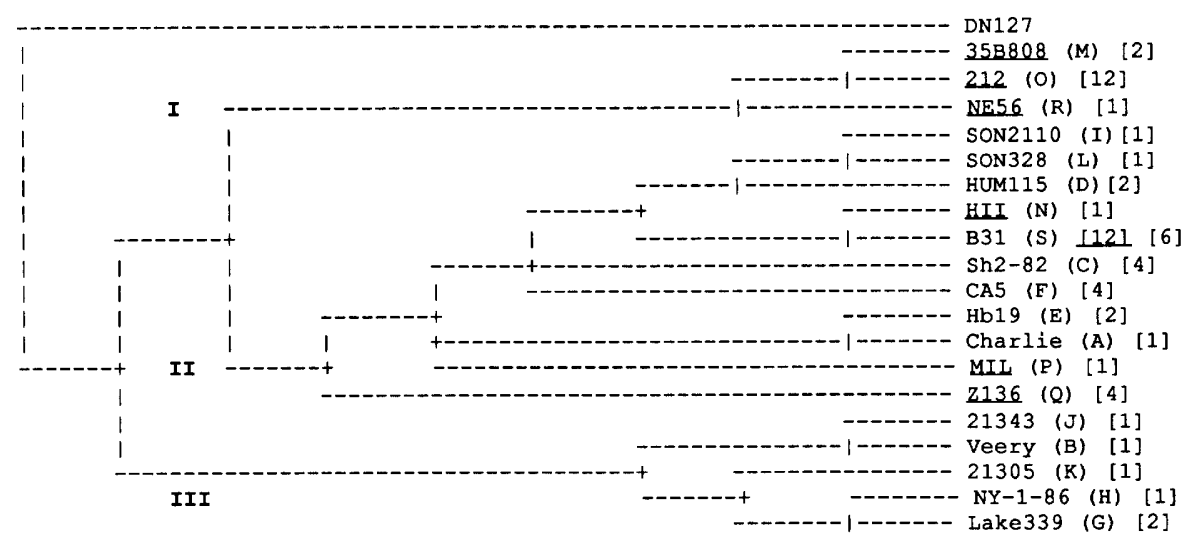

FIG. 5. Strict consensus of two trees obtained by maximum-parsimony analysis. The tree was generated from a reduced distance matrix for 20 taxa, each of which represented a PFGE polymorphism group, and was solved by the heuristics method contained within the PAUP package. The European strains are underlined. The number of isolates in each group is indicated in brackets. 


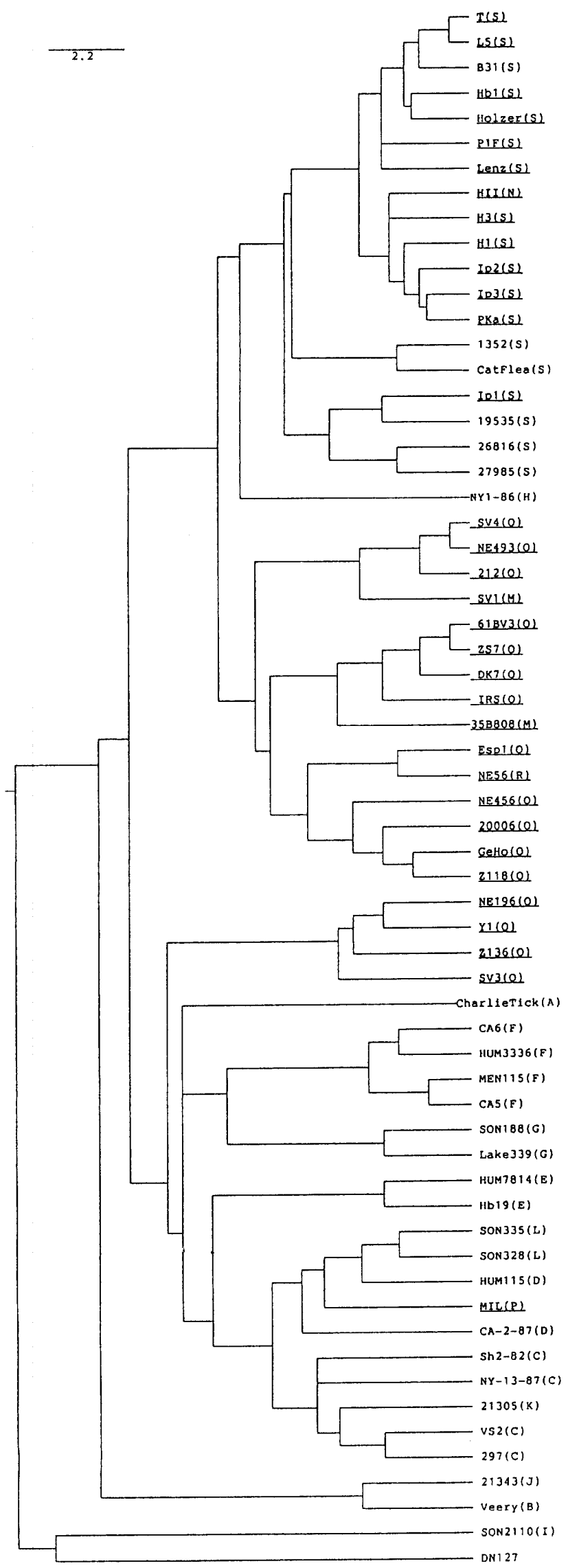

FIG. 6. Unweighted pair group with mathematical average rooted tree obtained with MEGA software from AP-PCR data matrix. The European strains are underlined.

and American strains evolved from a very recent common ancestor. The different groups of American strains are more heterogeneous since they belong to distinct lineages. The deeper branching of these strains on distance trees is consistent with the hypothesis that American strains have been evolving for a longer period of time than European strains and could be ancestors of European strains.

However, to confirm the genetic structure of the population within the species, an alternative strategy would be to analyze strains with methods involving a single gene locus. The results of an analysis of different sequences suggest that strains isolated on each side of the Atlantic Ocean are highly related one another. American strains $\mathrm{B} 31^{\mathrm{T}}(\mathrm{T}=$ type strain $)$ and $\mathrm{N} 40$ and European strain ZS7 exhibited 99 to $100 \%$ osp $A$ sequence identity $(16,32,34)$. American strains $\mathrm{B} 31^{\mathrm{T}}$ (accession number X15661) and HB19 (accession number X75200) and European strain GeHo (accession number X15660) exhibited more than

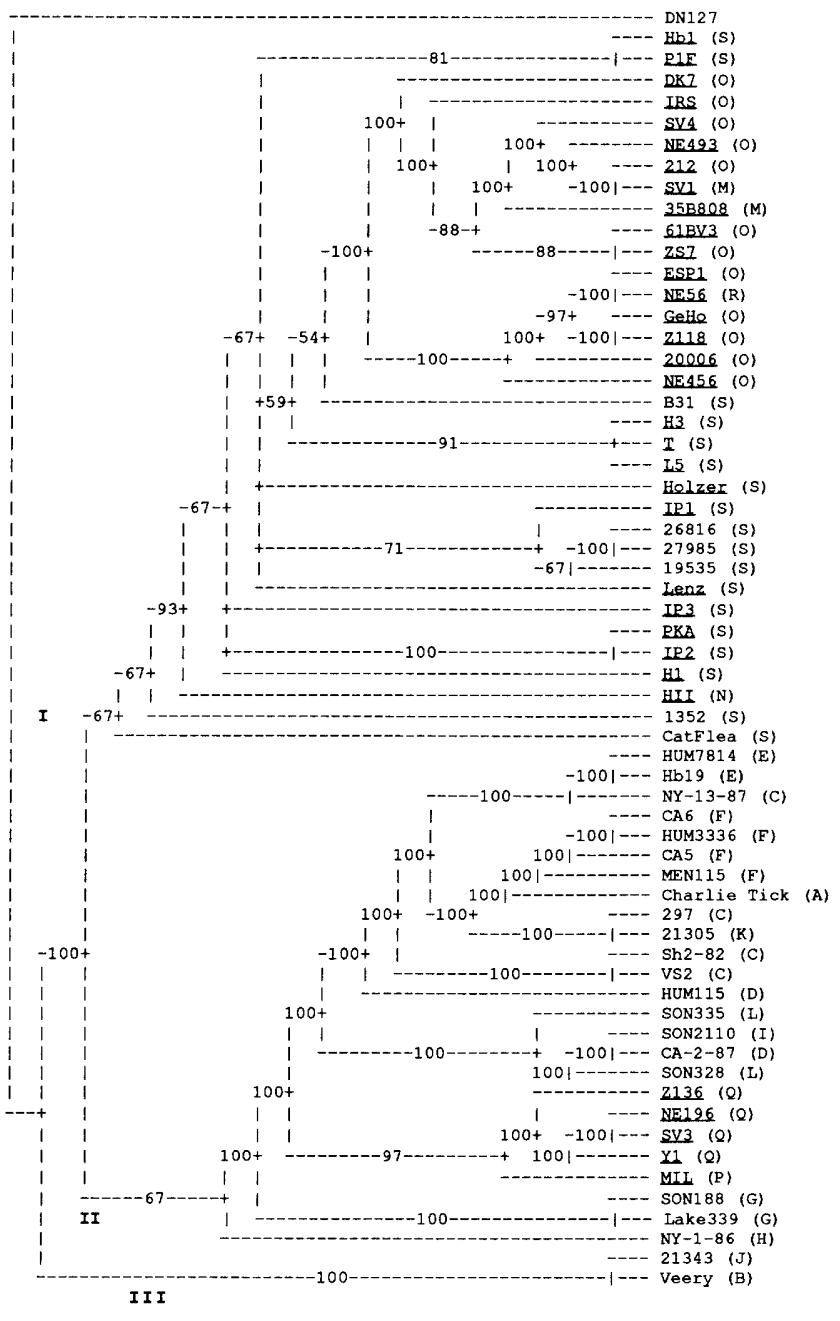

FIG. 7. $50 \%$ majority rule tree obtained from 100 shortest trees by parsimony analysis. The tree was based on an analysis of 4,278 characters ( 62 strains $\times 69$ characters) obtained by AP-PCR and was solved by the heuristics method contained within the PAUP package. The European strains are underlined. 
99\% fla sequence identity. Because of lateral transfer (19), many sequences of the variable $\operatorname{sp} C$ gene are available from data banks. A comparison of $o s p C$ sequences leads to the same conclusions as the analysis of PFGE and AP-PCR results. Livey et al. (19) detected more $\operatorname{osp} C$ types among American $B$. burgdorferi sensu stricto strains than among $B$. burgdorferi sensu stricto strains from Europe. It is interesting that strains classified in $o s p C$ restriction fragment length polymorphism type 2 by these authors all belong to unique PFGE polymorphism group $S$ and are closely related as determined by AP-PCR. As observed for the whole genome, a striking similarity was reported for the $\operatorname{sp} \mathrm{C}$ genes from strains isolated from distant geographic areas. For example, European strains IP2 (accession number L42887) and PKa (accession number X69589) and American strains $B 31^{\mathrm{T}}$ (accession number X69596) and 26816 (18) exhibit $100 \%$ ospC sequence identity. These strains fell into the same PFGE polymorphism group. Similarly, American strain BUR (accession number X84765) exhibited 98.7 and $96 \%$ sequence identity with European strains ZS7 (accession number L42868) and DK7 (accession number X73625), respectively $(15,19,27,28)$. Our results for the whole genomes of $B$. burgdorferi sensu stricto isolates and the analysis of gene sequence data from data banks lead to the conclusion that European strains are closely related to and therefore very recently diverged from a few American clones. In addition, in America, B. burgdorferi sensu stricto has been evolving for enough time to diverge into at least two genomospecies related to one another at borderline species level (22). This is not the case in Europe. B. burgdorferi sensu stricto has not been found in Asia. This leads us to suggest anteriority of American strains, some of which could have migrated to Europe very recently. Other epidemiological features favor of this hypothesis. The main symptoms of Lyme borreliosis initially reported in Europe were neurological manifestations which are now known to be preferentially due to $B$. garinii and late cutaneous lesions preferentially due to $B$. afzelii $(1,2,22,29)$. Arthritis associated with $B$. burgdorferi sensu stricto is still rare in Europe, was described only recently, and is predominant in western Europe, and these facts could reflect a slow extension of a recently imported $B$. burgdorferi sensu stricto population from America. An extensive study of relatively conserved genes, such as $\operatorname{osp} A$ and $f l a$, from a great number of strains from both continents could help confirm the hypotheses described above.

\section{ACKNOWLEDGMENTS}

We thank all people who supplied strains and R. Christen, I. Old, and $\mathrm{M}$. Theisen for critically reading the manuscript.

\section{REFERENCES}

1. Anthonissen, F. M., M. Dekesel, P. P. Hoet, and G. H. Bigaignon. 1994. Evidence for the involvement of different genospecies of Borrelia in the clinical outcome of Lyme disease in Belgium. Res. Microbiol. 145:327-331.

2. Assous, M. V., D. Postic, G. Paul, P. Névot, and G. Baranton. 1993. Western blot analysis of sera from Lyme borreliosis patients according to the genomic species of the Borrelia strains used as antigens. Eur. J. Clin. Microbiol. Infect. Dis. 12:261-268.

3. Baranton, G., D. Postic, I. Saint Girons, P. Boerlin, J. C. Piffaretti, M. Assous, and P. A. D. Grimont. 1992. Delineation of Borrelia burgdorferi sensu stricto, Borrelia garinii sp. nov., and group VS461 associated with Lyme borreliosis. Int. J. Syst. Bacteriol. 42:378-383.

4. Barbour, A. G. 1984. Isolation and cultivation of Lyme disease spirochetes. Yale J. Biol. Med. 57:521-525

5. Baril, C., J. C. Herrmann, C. Richaud, D. Margarita, and I. Saint Girons. 1992 Scattering of rRNA genes on the physical map of the circular chromosome of Leptospira interrogans serovar icterohaemorrhagiae. J. Bacteriol. 174:7566-7571.

6. Baril, C., C. Richaud, G. Baranton, and I. Saint Girons. 1989. Linear chromosome of Borrelia burgdorferi. Res. Microbiol. 140:507-516.

7. Belfaiza, J., D. Postic, E. Bellenger, G. Baranton, and I. Saint Girons. 1993. Genomic fingerprinting of Borrelia burgdorferi sensu lato by pulsed-field gel electrophoresis. J. Clin. Microbiol. 31:2873-2877.

8. Casjens, S., M. Delange, H. L. Ley III, P. Rosa, and W. M. Huang. 1995. Linear chromosomes of Lyme disease agent spirochetes: genetic diversity and conservation of gene order. J. Bacteriol. 177:2769-2780.

9. Davidson, B. E., J. Macdougall, and I. Saint Girons. 1992. Physical map of the linear chromosome of the bacterium Borrelia burgdorferi 212, a causative agent of Lyme disease, and localization of rRNA genes. J. Bacteriol. 174:3766-3774.

10. Felsenstein, J. 1989. PHYLIP-phylogeny inference package (version 3.2). Cladistics 5:164-166.

11. Ferdows, M. S., and A. G. Barbour. 1989. Megabase-sized linear DNA in the bacterium Borrelia burgdorferi, the Lyme disease agent. Proc. Natl. Acad. Sci. USA 86:5969-5973.

12. Fitch, W. 1971. Toward defining the course of evolution: minimal change for a specific tree topology. Syst. Zool. 20:406-416.

13. Fitch, W. M., and E. Margoliash. 1967. Construction of phylogenetic trees. Science 155:279-284.

14. Hyde, F. W., and R. C. Johnson. 1984. Genetic relationship of Lyme disease spirochetes to Borrelia, Treponema, and Leptospira spp. J. Clin. Microbiol. 20:151-154.

15. Jauris-Heipke, S., G. Liegl, V. Preac-Mursic, D. Röbler, E. Schwab, E. Soutschek, G. Will, and B. Wilske. 1995. Molecular analysis of genes encoding outer surface protein $\mathrm{C}(\mathrm{OspC})$ of Borrelia burgdorferi sensu lato: relationship to $\operatorname{csp} A$ genotype and evidence of lateral gene exchange of $\operatorname{sspC}$. J. Clin. Microbiol. 33:1860-1866.

16. Jonsson, M., L. Noppa, A. G. Barbour, and S. Bergström. 1992. Heterogeneity of outer membrane proteins in Borrelia burgdorferi: comparison of osp operons of three isolates of different geographic origins. Infect. Immun. 60:1845-1853.

17. Kumar, S., K. Tamura, and N. Masatoshi. 1993. MEGA: molecular evolutionary genetics analysis, version 1.01. The Pennsylvania State University, University Park.

18. Livey, I. 1996. Personal communication.

19. Livey, I., C. P. Gibbs, R. Schuster, and F. Dorner. 1995. Evidence for lateral transfer and recombination in OspC variation in Lyme disease Borrelia. Mol. Microbiol. 18:257-269.

20. Marconi, R. T., D. Liveris, and I. Schwartz. 1995. Identification of novel insertion elements, restriction fragment length polymorphism patterns, and discontinuous 23S rRNA in Lyme disease spirochetes: phylogenetic analyses of rRNA genes and their intergenic spacers in Borrelia japonica sp. nov. and genomic group 21038 (Borrelia andersonii sp. nov.) isolates. J. Clin. Microbiol. 33:2427-2434

21. Olsen, B., D. C. Duffy, T. G. T. Jaenson, A. Gylfe, J. Bonnedahl, and S. Bergström. 1995. Transhemispheric exchange of Lyme disease spirochetes by seabirds. J. Clin. Microbiol. 33:3270-3274.

22. Postic, D., M. V. Assous, P. A. D. Grimont, and G. Baranton. 1994. Diversity of Borrelia burgdorferi sensu lato evidenced by restriction fragment length polymorphism of $r f(5 S) r l(23 S)$ intergenic spacer amplicons. Int. J. Syst. Bacteriol. 44:743-752.

23. Saitou, N., and M. Nei. 1987. The neighbor-joining method: a new method for reconstructing phylogenetic trees. Mol. Biol. Evol. 4:406-425.

24. Sneath, P. H. A., and R. R. Sokal. 1973. Numerical taxonomy. Freeman, San Francisco, Calif.

25. Southern, E. M. 1975. Detection of specific sequences among DNA fragments separated by gel electrophoresis. J. Mol. Biol. 98:503-517.

26. Swofford, D. L. 1992. PAUP: phylogenic analysis using parsimony, version 3.0. Illinois Natural History Survey, Champaign.

27. Theisen, M., M. Borre, M. J. Mathiesen, B. Mikkelsen, A. M. Lebech, and K. Hansen. 1995. Evolution of the Borrelia burgdorferi outer surface protein OspC. J. Bacteriol. 177:3036-3044.

28. Theisen, M., B. Frederiksen, A. M. Lebech, J. Vuust, and K. Hansen. 1993. Polymorphism in $o s p C$ gene of Borrelia burgdorferi and immunoreactivity of OspC protein: implications for taxonomy and for use of OspC protein as a diagnostic antigen. J. Clin. Microbiol. 31:2570-2576.

29. Van Dam, A. P., H. Kuiper, K. Vos, A. Widjojokusumo, B. M. de Jongh, L. Spanjaard, A. C. P. Ramselaar, M. D. Kramer, and J. Dankert. 1993. Different genospecies of Borrelia burgdorferi are associated with distinct clinical manifestations of Lyme borreliosis. Clin. Infect. Dis. 17:708-717.

30. Welsh, J., and M. MeClelland. 1990. Fingerprinting genomes using PCR with arbitrary primers. Nucleic Acids Res. 18:7213-7218.

31. Welsh, J., C. Pretzman, D. Postic, I. Saint Girons, G. Baranton, and M. McClelland. 1992. Genomic fingerprinting by arbitrarily primed polymerase chain reaction resolves Borrelia burgdorferi into three distinct phyletic groups. Int. J. Syst. Bacteriol. 42:370-377.

32. Wilske, B., V. Preac-Mursic, U. B. Göbel, B. Graf, S. Jauris, E. Soutschek, E. Schwab, and G. Zumstein. 1993. An OspA serotyping system for Borrelia burgdorferi based on reactivity with monoclonal antibodies and OspA sequence analysis. J. Clin. Microbiol. 31:340-350.

33. Xu, Y., and R. C. Johnson. 1995. Analysis and comparison of plasmid profiles of Borrelia burgdorferi sensu lato strains. J. Clin. Microbiol. 33:2679-2685.

34. Zumstein, G., R. Fuchs, A. Hofmann, V. Preac-Mursic, E. Soutschek, and B. Wilske. 1992. Genetic polymorphism of the gene encoding the outer surface protein A (OspA) of Borrelia burgdorferi. Med. Microbiol. Immunol. 181:57-70. 